Fourth International Conference on Sustainable Construction Materials and Technologies http://www.claisse.info/Proceedings.htm

SCMT4

Las Vegas, USA, August 7-11, 2016

\title{
Performance of Corrosion-Aged Reinforced Concrete (RC) Beams Rehabilitated with Fabric-Reinforced Cementitious Matrix (FRCM)
}

\author{
Mohammed Elghazy ${ }^{1 \mathrm{a}}$, Ahmed El Refai ${ }^{1 \mathrm{~b}}$, Usama A. Ebead ${ }^{2}$, and Antonio Nanni ${ }^{3}$ \\ ${ }^{1}$ Laval University - 1065 Avenue de la Médecine, Quebec, G1V 0A6, Canada. \\ ${ }^{l a}$ Email: 〈mohammed.elghazy.1@ulaval.ca〉, ${ }^{1 a}$ Email: 〈ahmed.elrefai@gci.ulaval.ca〉. \\ ${ }^{2}$ Qatar University - P.O. Box 2713, Doha, Qatar. ${ }^{2}$ Email: 〈uebead@qu.edu.qa>. \\ ${ }^{3}$ University of Miami - 1251 Memorial Drive, FL, USA 33146. ${ }^{3}$ Email: <nanni@miami.edu>.
}

\begin{abstract}
This paper reports on the feasibility of using fabric-reinforced cementitious matrix (FRCM) systems to rehabilitate corrosion-damaged reinforced concrete (RC) beams. Seven large-scale RC beams were constructed and tested to failure under four-point load configuration. Six beams were subjected to an accelerated corrosion process for 70 days to obtain an estimated mass loss of $10 \%$ in the tensile steel reinforcing bars. One virgin beam and one corroded unrepaired beam were used as benchmarks for comparison purpose. The other five corroded beams were repaired before applying the FRCM system. The test parameters included the number of fabric plies $(1,2$, and 4) and the strengthening schemes (endanchored bottom flexural strips and fully U-wrapped flexural strips). Test results showed that corrosion insignificantly reduced the yield and the ultimate strength of the specimen. However, the corroded specimen failed to meet the provisions of the ACI 318 code for crack width criteria. The use of FRCM increased the ultimate capacity of corroded beams between $6 \%$ and $46 \%$ and their yield strength up to $20 \%$ in comparison with those of the control virgin beam. The specimens repaired with U-wrapped FRCM strips showed higher capacity and higher ductility than those repaired with the end-anchored bottom strips having similar number of layers. A higher gain in the flexural capacity and a lower ductility index were reported for specimens with higher amount of FRCM layers.
\end{abstract}

\section{INTRODUCTION}

Corrosion of steel reinforcing bars is an inevitable phenomenon caused by the exposure to harsh environmental conditions and the use of de-icing salts especially in North America. Many traditional techniques have been used to repair and strengthen corrosion-aged reinforced concrete (RC) structures such as the replacement of the corroded bars and the deteriorated concrete substrate, the use of externally bonded steel plates, and more recently the use of epoxy-bonded fiber-reinforced polymers (FRP). The use of FRPs in strengthening RC structures has proved its efficiency due to the superior properties of the FRP materials. Many studies have documented their feasibility and advantages as strengthening materials (Baggio et al. 2014; Dong et al. 2013; Dong et al. 2012; Masoud \& Soudki 2006). However, problems associated with 
the use of FRP have also been reported by many researchers. Among the drawbacks of FRPs systems are the poor fire resistance (Hashemi and Al-Mahaidi 2012), the incompatibility with the concrete substrate (Al-Salloum et al. 2012), and the loss of ductility (Hashemi \& Al-Mahaidi 2012a). In order to overcome these drawbacks, the use of fabric-reinforced cementitious matrix (FRCM) systems have been introduced as a promising strengthening and repair technique.

FRCM systems are innovative composites made of cement-based matrix reinforced with continuous fibers. They have recently emerged as a viable technology for repairing and strengthening RC and masonry structures. FRCM is a composite system consisting of one or more fabric mesh embedded in cement-based matrix (serving as binder). The fabric or grid, is made of long dry-woven fibers in one or two orthogonal directions. The embedded grid is shielded between the mortar layers thus minimizing its fire vulnerability. In addition, the compatibility between the mortar used and the concrete substrate is inherited since both materials have the cement as a common base. The cement-based mortar used in FRCM acts as a barrier against chloride ions penetration thus protecting the main reinforcing bars from corrosion attack. Its lightweight, high tensile strength, and ease of application makes the system very appealing to engineers.

The effectiveness of FRCM as a strengthening technique for undamaged RC flexural elements has been reported by many researchers (Babaeidarabad et al. 2014; Loreto et al. 2013; Al-Salloum et al. 2012; Schladitz et al. 2012; D’Ambrisi \& Focacci 2011; Brückner et al. 2006). None of these studies has reported on the performance of corrosion-damaged concrete elements strengthened with FRCM systems. Recently, one study (El-Maaddawy and Elrefai 2016) documented the effectiveness of using basalt and carbon FRCM systems in restoring the ultimate capacity of corroded RC T-beams. However, the influence of various parameters on the performance of the strengthened beams was not fully documented.

The present work is a part of a large study that aims at investigating the short-term, long-term, and the fatigue performance of corroded beams repaired with different FRCM systems prior to being recommended for field applications. In this paper, the flexural behavior (short-term) of corroded beams repaired with one FRCM system having different number of plies and repair configurations is reported. The obtained results report on the failure modes, the strength, and the ductility of the repaired specimens.

\section{EXPERMENTAL INVESTIGATION}

Table 1 shows the test matrix. Seven large-scale RC beams were constructed and tested. One specimen was neither corroded nor repaired (UU), another one was corroded but not repaired (CU), and five specimens were corroded then repaired with different amounts and schemes of FRCM. The test parameters of this study were the number of FRCM plies (1,2, and 4 plies) and the repair scheme (scheme I and II).

\section{Description of Test Specimen}

The test specimen was $2.80 \mathrm{~m}$ long with a $150 \times 250 \mathrm{~mm}$ rectangular cross section. All beams were reinforced with $2-15 \mathrm{M}$ deformed bars at the bottom, $2-8 \mathrm{M}$ deformed bars at the top, and $10 \mathrm{M}$ deformed stirrups spaced at $100 \mathrm{~mm}$. A hollow stainless steel tube with external and internal diameters of $9.5 \mathrm{~mm}$ and $7 \mathrm{~mm}$, respectively, was placed at $80 \mathrm{~mm}$ from the specimen tension face to act as a cathode during the accelerated corrosion process. All of the specimens were subjected to four-point load configuration with a constant moment span of $800 \mathrm{~mm}$ and a shear span of $880 \mathrm{~mm}$. Typical dimension and reinforcement details of the test specimen are shown in Figure 1.

\section{Accelerated Corrosion}

Corrosion of main reinforcement was localized in the middle $1200 \mathrm{~mm}$ of the beam's span. Salt $(\mathrm{NaCl})$ measured as $5 \%$ of the cement weight was added to the concrete mix along the middle-bottom of each specimen. A power supply was used to impress a constant electrical current of $380 \mathrm{~mA}$ (milliamps) to obtain 
a current density of $180 \mu \mathrm{A} / \mathrm{cm}^{2}$ in the reinforcing bars. During the accelerated corrosion process, the bottom reinforcement acted as anode whereas the stainless steel tube acted as cathode and the salted concrete acted as electrolyte. All corroded specimens were subjected to wet-dry cycles that consisted of 3 days wet and 4 days dry in a large environmental chamber.

Faraday's law that relates the mass loss to the current intensity and the duration of corrosion was used to calculate the predicted mass loss in the steel bars. In this study, a 10\% mass loss was anticipated to represent minor corrosion damage. According to Faraday's law, the required duration of corrosion exposure was 70 days.

Table 1. Test Matrix and Summary of Test Results

\begin{tabular}{|c|c|c|c|c|c|c|}
\hline Specimen & $\begin{array}{c}\text { No. of } \\
\text { FRCM } \\
\text { plies }\end{array}$ & $\begin{array}{c}\mathrm{P}_{\mathrm{y}} \\
(\mathrm{KN})\end{array}$ & $\begin{array}{c}\mathrm{P}_{\mathrm{u}} \\
(\mathrm{KN})\end{array}$ & $\begin{array}{c}\text { Enhancement } \\
\text { ratio in } \mathrm{P}_{\mathrm{y}}\end{array}$ & $\begin{array}{c}\text { Enhancement } \\
\text { ratio in } \mathrm{P}_{\mathrm{u}}\end{array}$ & Mode of failure \\
\hline $\mathrm{UU}$ & - & 72.9 & 78.3 & & & $\begin{array}{c}\text { Concrete crushing after } \\
\text { steel yielding }\end{array}$ \\
\hline $\mathrm{CU}$ & - & 69.5 & 76.1 & $-4.9 \%$ & $-2 \%$ & $\begin{array}{c}\text { Concrete crushing after } \\
\text { steel yielding }\end{array}$ \\
\hline $\mathrm{CR}-1-\mathrm{I}$ & 1 & 71.1 & 82.9 & $-2.5 \%$ & $6 \%$ & FRCM delamination \\
\hline $\mathrm{CR}-2-\mathrm{I}$ & 2 & 79.5 & 86.4 & $8.3 \%$ & $10.4 \%$ & FRCM delamination \\
\hline $\mathrm{CR}-4-\mathrm{I}$ & 4 & 83.3 & 99.6 & $12.5 \%$ & $27.3 \%$ & $\begin{array}{c}\text { FRCM delamination } \\
\text { after FRCM slippage at } \\
\text { the end anchorage }\end{array}$ \\
\hline $\mathrm{CR}-2-\mathrm{II}$ & 2 & 85.4 & 102.2 & $14.6 \%$ & $30.6 \%$ & $\begin{array}{c}\text { Slippage of fabric } \\
\text { within matrix }\end{array}$ \\
\hline
\end{tabular}

* UU, CU, and CR refer to Uncorroded-Unrepaired, Corroded-Unrepaired, and, Corroded-Repaired, respectively. I, 2 and 4 refer to the number of FRCM plies. I and II refer to the repair schemes I and II, respectively.

$P_{y}$ and $P_{u}$ are the yield and ultimate loads, respectively.
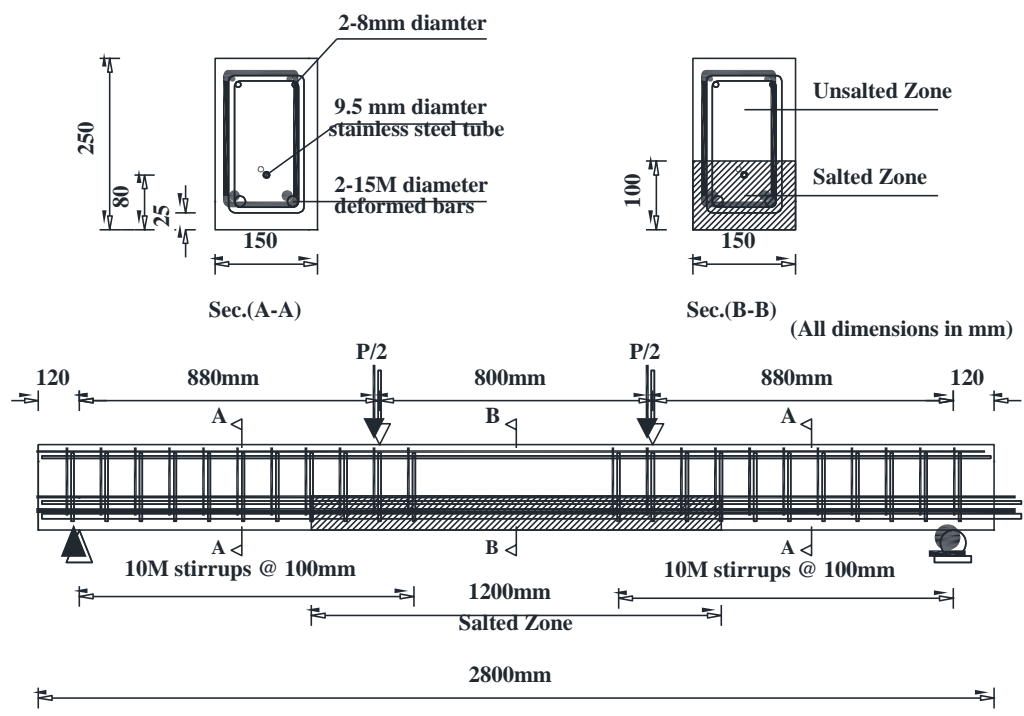

Figure 1. Typical Dimensions and Reinforcement Details of Test Specimens 


\section{Materials}

Two ready concrete mixes (normal and salted) with the same water/cement ratio were used to cast the beams. Standard concrete cylinders were prepared from each concrete batch and were tested under compression load after 28 days and after 6 months of the casting date. Table 2 lists the compressive strength of the normal and salted concrete. The nominal yield strength of the reinforcement steel bars was $400 \mathrm{MPa}$ with an elastic modulus of $200 \mathrm{GPa}$.

Table 2. Concrete Compressive Strength

\begin{tabular}{|c|c|c|c|}
\hline & Compressive strength & Standard deviation & Coefficient of variation \\
\hline Normal concrete (28day) & $37.9 \mathrm{MPa}$ & $0.8 \mathrm{MPa}$ & $2 \%$ \\
\hline Salted concrete (28day) & $33.5 \mathrm{MPa}$ & $1.1 \mathrm{MPa}$ & $3.2 \%$ \\
\hline Normal concrete (6 month) & $41.8 \mathrm{MPa}$ & $4.8 \mathrm{MPa}$ & $11.4 \%$ \\
\hline Salted concrete (6 month) & $41.2 \mathrm{MPa}$ & $0.6 \mathrm{MPa}$ & $1.6 \%$ \\
\hline
\end{tabular}

\section{Fabric-Reinforced Cementitious Matrix (FRCM)}

PBO-FRCM system consisting of Polyparaphenylene benzobisoxazole (PBO) fabric and a cementitious matrix was used in this study. The fabric was an unbalanced net of spaced fiber roving organized along two orthogonal directions as shown in Figure 2. The roving has a width of $5 \mathrm{~mm}$ and $2.5 \mathrm{~mm}$ in the main (longitudinal) direction and the secondary (transverse) direction, respectively. Spacing between the roving is approximately 5 and $15 \mathrm{~mm}$ in the main and secondary directions, respectively. The fabric has nominal thickness of $0.046 \mathrm{~mm}$ and $0.011 \mathrm{~mm}$ in the main and secondary directions, respectively. The main direction of fabric has an equivalent fiber area per unit width $50 \mathrm{~mm}^{2} / \mathrm{m}$. The mechanical properties of the PBOfabric according to the data sheet provided by the manufacturer are given in Table 3 .

The matrix used with the PBO-fabric was a cement-based matrix made of composite high-fineness cement binder, adhesion promoter, inorganic nanoparticle, micro aggregates, and high-effectiveness polycarboxylic water-reducing admixtures, as reported by the manufacturer. Tests conducted by authors on standard cylinders and prisms showed a 28-day compressive strength of $43.86 \mathrm{MPa}$ with a standard deviation of $0.41 \mathrm{Mpa}$ and flexural strength of $3.01 \mathrm{MPa}$ with a standard of deviation of $0.32 \mathrm{MPa}$.

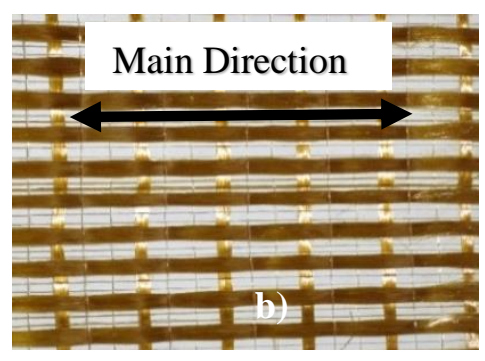

Figure 2. PBO Fabric Used in this Study

Table 3. Mechanical Properties of PBO-Fabric (Adapted from manufacturer's data sheet).

\begin{tabular}{|c|c|}
\hline Properties & PBO- Fabric \\
\hline Tensile strength [GPa] & 5.8 \\
\hline Elastic modulus (E) [GPa] & 270 \\
\hline Ultimate strain [\%] & 2.15 \\
\hline
\end{tabular}




\section{FRCM Repair Technique}

All of the corroded test specimens were patchily repaired before applying the FRCM composite. The deteriorated concrete due to corrosion of the main reinforcement was removed using hydraulic hammer as shown in Figure 3 (a). The corroded steel bars were then cleaned using steel brush. The beams were repaired using commercial cementitious repair mortar with compressive strength of $55.36 \mathrm{MPa}$ (standard deviation of 4.97 MPa) and flexural strength of $3.36 \mathrm{MPa}$ (standard deviation of $0.26 \mathrm{MPa}$ ) as shown in Figure 3 (b). Dry sandblasting was used to roughen the repaired surface before applying the FRCM system. The repaired substrate was damped in water for 2 hours before applying the first layer of the cementitious matrix with a thickness of 3 to $4 \mathrm{~mm}$. Then, the fabric was installed and coated with a second layer of the matrix with similar thickness as shown in Figure 3 (c). The procedure is then repeated according to the number of layers specified.
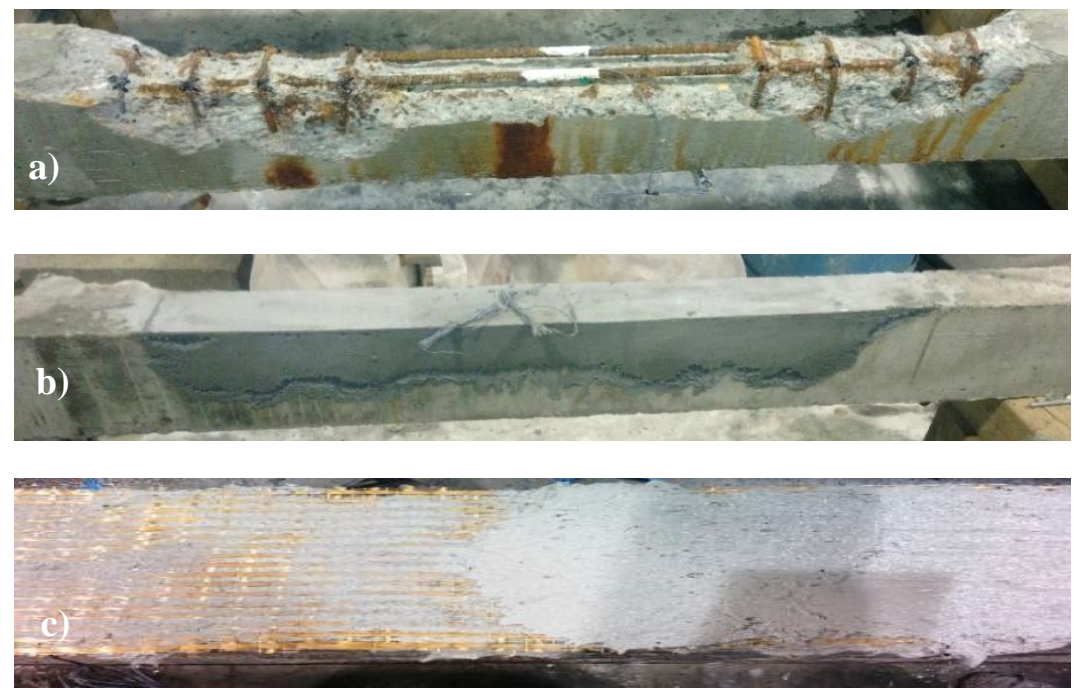

\section{Figure 3. FRCM Repair Procedure: a) Removing the Deteriorated Concrete, b) Patch Repair, and c) FRCM Application}

\section{FRCM Repair Schemes}

Two strengthening schemes were used as shown in Figure 4. Scheme I consisted of one or more FRCM flexure plies having $150 \mathrm{~mm}$ width and applied to the tension face of the beam over a length of $2400 \mathrm{~mm}$. The fabric was oriented so as its main direction was parallel to the longitudinal axis of the specimens. One U- shaped transverse strip of FRCM of $300 \mathrm{~mm}$ width was bonded around the cross section of the beam to act as an anchorage for the flexure plies. Scheme II consisted of bottom flexural strips as in scheme I, but with a U-shaped continuous ply that was wrapped along the beam's span. The strong direction of the Uwrapped fabric was oriented parallel the longitudinal axis of the beams to be counted as flexural ply.

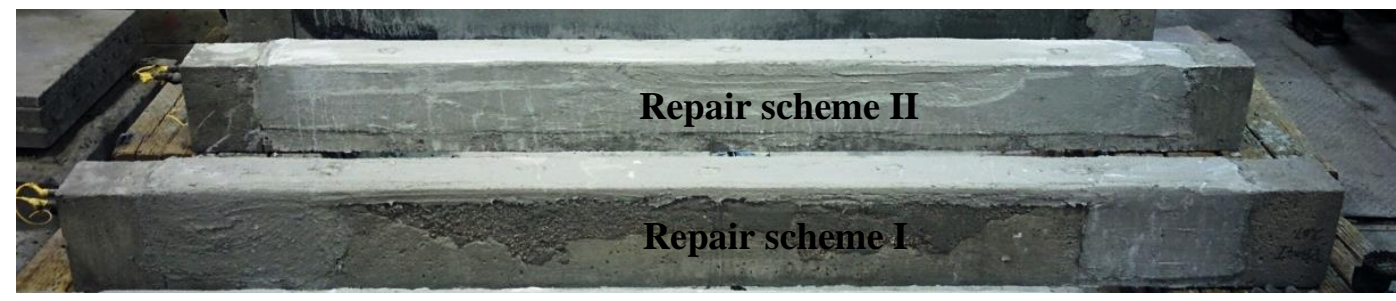

Figure 4. FRCM Repair Schemes 


\section{Test Setup and Instrumentation}

A four-point flexure test configuration was used during testing. The load was applied in displacement control at a rate of $2 \mathrm{~mm}$ per minute using a MTS actuator. Beam deflections were measured by means of three linear variable differential transducers (LVDTs) at the mid-span and under the point loads. All beams were instrumented at mid-span with a $60 \mathrm{~mm}$ long strain gauge bonded to the top concrete surface and 5 $\mathrm{mm}$ long strain gauges bonded to the main steel bars. In addition, for beams strengthened with FRCM, a 5 $\mathrm{mm}$ strain gauge was applied directly on the outer fabric at the beam's mid-span.

\section{TEST RESULTS AND DISCUSSION}

\section{Corrosion Cracks and Mass Loss}

Visible continuous longitudinal cracks parallel to the bottom reinforcing bars with maximum and average widths of $1 \mathrm{~mm}$ and $0.7 \mathrm{~mm}$, respectively, were observed at the end of corrosion process. No cover spalling was noticed. All of the corroded specimens failed to meet the ACI 318 service requirement that limits the maximum allowable crack width for a reinforced concrete beam in service to $0.50 \mathrm{~mm}$.

Visual inspection of the corroded beams revealed the existence of several corrosion pits that were randomly distributed along the surface of the corroded bars. Five steel coupons, $200 \mathrm{~mm}$ long each, were extracted from the corroded bars after testing. Their actual mass loss was determined according to ASTM G1-03 (ASTM 2011). The average, maximum, and minimum tensile steel mass loss determined were 11.6\%, $12.9 \%$, and $10.4 \%$, respectively.

\section{Modes of Failure}

The failure modes of the tested specimens are summarized in Table 1 and shown in Figure 5. The control specimen (UU) and the corroded unrepaired specimen (CU) showed a typical mode of failure of an underreinforced beam in which large flexural cracks appeared in the constant moment zone after steel yielding as shown in Figure 5 (a) for the UU specimen.

Prefect bond between the repair mortar and the concrete substrate was reported for all repaired beams. Based on the test observations, two different modes were reported for the repaired beams namely, (1) delamination of FRCM at the fabric/matrix interface in the maximum bending moment zone as shown in Figure 5 (b), and (2) significant slippage of fabric within the matrix in specimens repaired with scheme II as shown in Figure 5 (c).

In the first mode of failure, the delamination was caused by the propagation of the flexural cracks to the first layer of the cementitious matrix and the relative deformation between the fabric and the matrix. This mode of failure was reported for the specimens CR-1-I and CR-2-I. After FRCM delamination, the load dropped and the behavior of the specimens reflected that of the control specimen. In the second mode of failure, flexural cracks started to propagate first in the matrix followed by gradual slippage of fabric until the FRCM strengthening action was lost. This failure mode has been observed in all of the specimens that were strengthened with scheme II and also in the specimen CR-4-I where large fiber/matrix slip was reported at the end anchor followed by de-bonding at the fabric/matrix interface in the constant moment zone. 

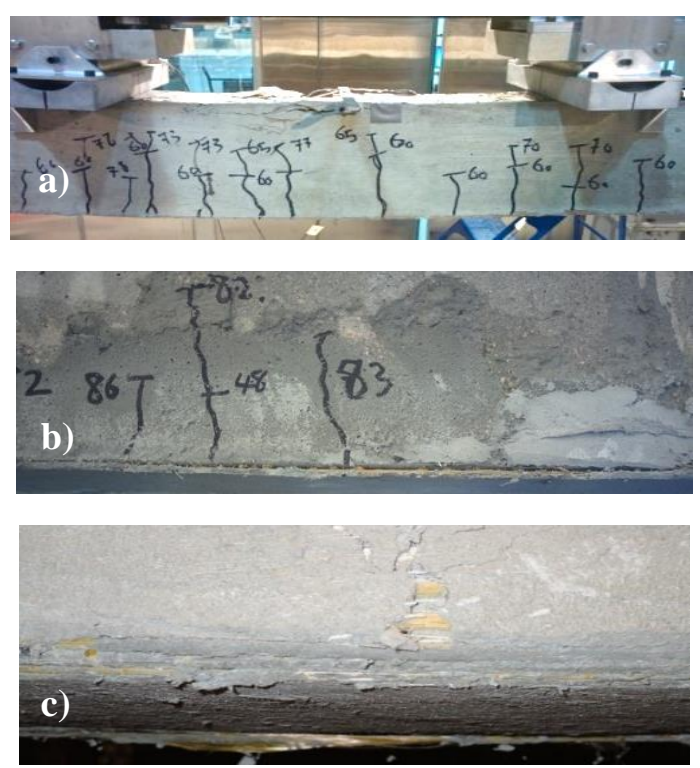

Figure 5. Modes of Failure: a) Concrete Crushing after Steel Yielding for the UU Specimen; b) FRCM Delamination for the CR-2-I Specimen; and c) Slippage of Fabric within Matrix in the CR-4-II Specimen

\section{Load-Deflection Response}

Table 1 shows the ultimate load $\left(\mathrm{P}_{\mathrm{u}}\right)$, the yield load $\left(\mathrm{P}_{\mathrm{y}}\right)$, and the enhancement ratio in $\mathrm{P}_{\mathrm{u}}$ and $\mathrm{P}_{\mathrm{y}}$ compared to the control specimen. The enhancement in the flexural response was highly dependent on the FRCM repair scheme and the number of FRCM layers applied. Figure 6 illustrates the effect of the number of FRCM plies with scheme I on the flexural response of the strengthened specimens. The effect of FRCM scheme (Scheme I and II) on the load-deflection response of the strengthened specimens having two and four FRCM plies is shown in Figure 7. Uncorroded and corroded data are also shown for reference. It is worth noting that average mass loss of $11.6 \%$ due to corrosion reduced the yield and ultimate loads by $5 \%$ and $2 \%$ respectively.

Figure 6 illustrates that increasing the number of FRCM plies using scheme I increased the yielding and the ultimate strength of the repaired specimens but decreased their ductility at different ratios. The use of one ply of FRCM in specimen CR-1-I restored 106\% and 97.5\% of the ultimate and yield strength of the control virgin specimen, respectively. The use of two layers of FRCM in specimen CR-2-I increased the yielding and the ultimate load capacity by $8.3 \%$ and $10.4 \%$, respectively, and the maximum deflection by $6 \%$ compared to those of the control specimen. Specimen CR-4-I had yielding and ultimate strength higher than those of the control specimen by $12.5 \%$ and $27.3 \%$, respectively, with similar maximum deflection.

As shown in Figure 7, the enhancement in the ultimate capacity of the strengthened beams having two layers of FRCM (CR-2-I and CR-2-II) was $10.4 \%$ and $30.6 \%$ for repair scheme I and II respectively. The yield load increased by $8.3 \%$ and $14.6 \%$ for repair scheme I and II respectively. Specimens repaired with four layers of FRCM exhibited superior performance in comparison with all other specimens. The use of four layers of FRCM with scheme II (specimen CR-4-II) increased the yielding and the ultimate load capacity by $20.1 \%$ and $46 \%$, respectively in comparison to $12.5 \%$ and $27.3 \%$ of specimen CR-4-I having similar number of fabric layers. This result demonstrated that the repair scheme II was more efficient than scheme I in improving the yielding and ultimate loads as well as the ductility of the repaired specimens. This can be related to the effect of the continuous wrapping layer in delaying the delamination of the FRCM. 


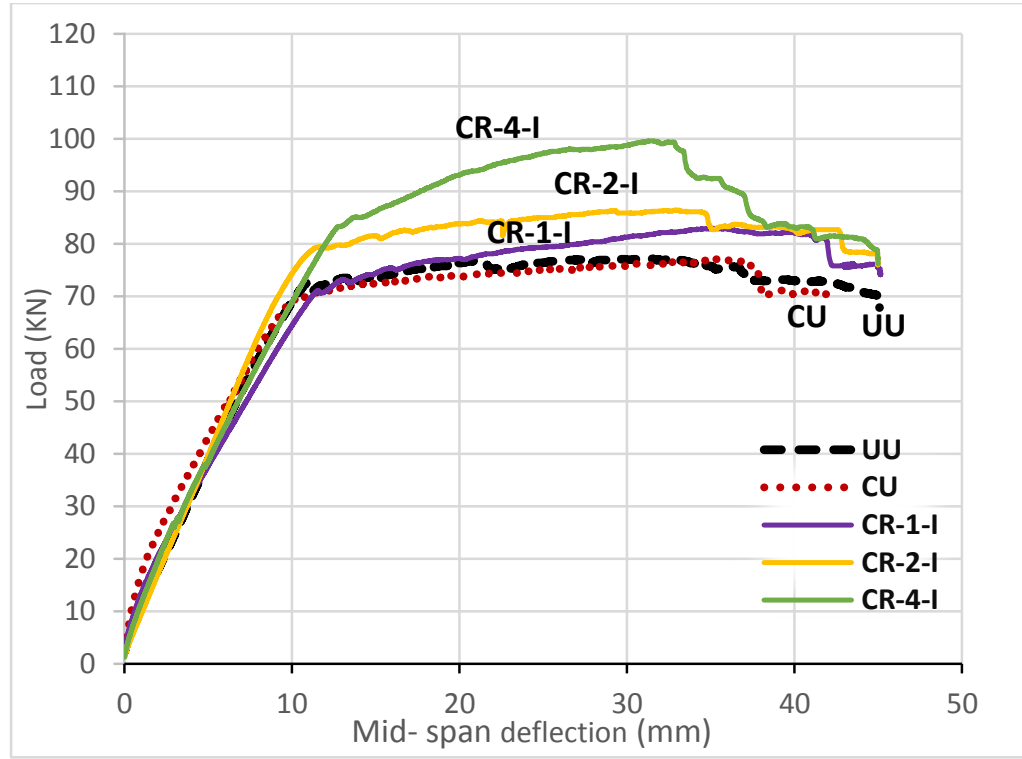

Figure 6. Effect of Number of FRCM Plies with Scheme I on the Load-Deflection Curve

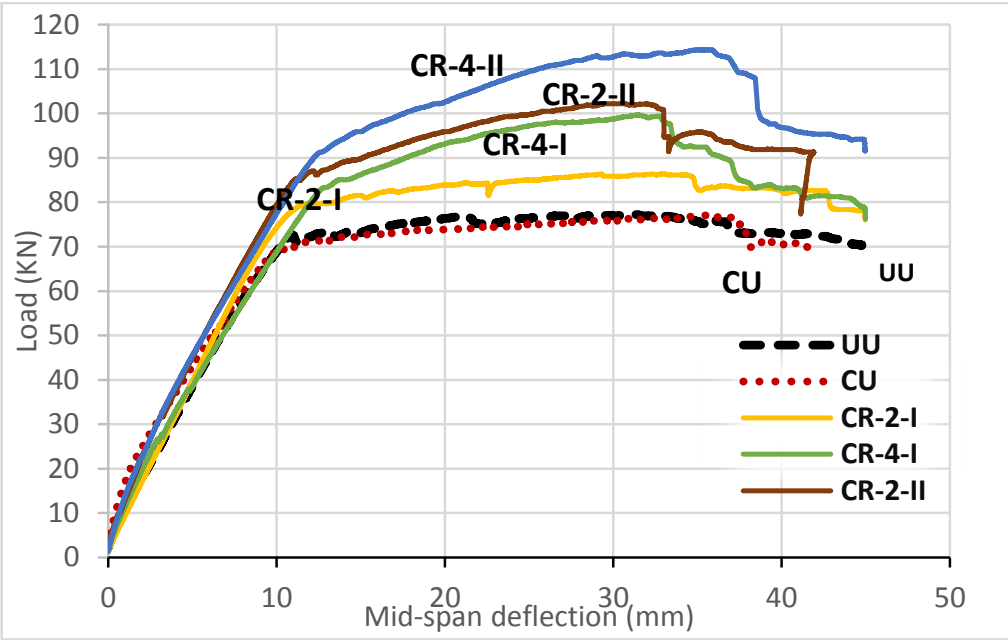

\section{Figure 7. Effect of FRCM Repair Scheme (Scheme I and II) on the Load-Deflection Curve}

\section{Ductility Performance}

The ductility index was used to evaluate the ductility of the tested specimens, which is the ratio of the beam deflection at ultimate to its deflection at yielding. In general, the higher ductility index means a higher ability of the beam to redistribute moment and to increase global deformation and energy dissipation. Table 4 lists the deflections, the ductility indices, and the ductility index of each beam normalized to that of the control specimen UU.

Corrosion of steel bars increased the ductility index of the specimen CU by $21 \%$ in comparison to that of the control specimen. For specimens repaired with scheme I, as the number of the FRCM plies increased the ductility index decreased. For example, the ductility index of the specimens CR-4-I was lower than that of specimen CR-1-I by 25\%. Increasing the number of FRCM plies in scheme II has insignificant effect on 
the ductility index. The ductility index of specimen CR-4-II was $11 \%$ higher than that of specimen CR-4-I with the same amount of FRCM plies used.

Table 4. Ductility Results

\begin{tabular}{|c|c|c|c|c|}
\hline \multirow{2}{*}{ Specimen } & \multicolumn{2}{|c|}{ Deflection values $(\mathrm{mm})$} & \multirow{2}{*}{ Ductility index } & \multirow{2}{*}{ Normalized ductility index $^{\mathrm{a}}$} \\
\cline { 2 - 3 } & Yield & Ultimate & & 1 \\
\hline UU & 11 & 31.2 & 2.84 & 1.21 \\
\hline CU & 10.3 & 35.7 & 3.45 & 1.07 \\
\hline CR-1-I & 11.6 & 35.2 & 3.04 & 0.97 \\
\hline CR-2-I & 11.8 & 33.0 & 2.79 & 0.85 \\
\hline CR-4-I & 12.9 & 31.5 & 2.44 & 0.94 \\
\hline CR-2-II & 11.2 & 31.2 & 2.81 & 0.98 \\
\hline CR-4-II & 12.7 & 35.5 & 2.80 & \\
\hline
\end{tabular}

${ }^{a}$ with respect to the ductility index of the control beam

\section{CONCLUSION}

The current exploratory study highlighted the effectiveness of using FRCM systems as a repair technique for corrosion-damaged RC beams. FRCM systems successfully enhanced the structural performance of the tested beams. The conclusions drawn from the test results are as follow:

- An average tensile steel mass loss $11.6 \%$ reduced the yield load and the ultimate load of the beam by $5 \%$ and $2 \%$, respectively. The corroded-unrepaired beam showed a typical under-reinforced mode of failure with $20 \%$ higher ductility index compared to that of the control beam.

- Enhancement of the structural performance of corrosion-damaged RC beams depends on the repair scheme and the number of the FRCM layers used.

- The flexural capacity increased by $10.4 \%$ (2 plies) and 27\% (4 plies) for specimens repaired with scheme I, and $30.6 \%$ ( 2 plies) and 46\% (4 plies) for specimens repaired with scheme II, respectively, as compared to the control unstrengthened beam.

- Delamination of FRCM due to debonding at the fabric/matrix interface and slippage of fabric within the matrix were identified as two different modes of failure for the strengthened beams.

- The use of four plies of FRCM decreased the ductility index by $26 \%$ in comparison to that of the specimen repaired with one ply having the same repair scheme.

The research currently conducted by the authors will evaluate the flexural response of severely corroded RC beams strengthened with different types of FRCM systems.

\section{ACKNOWLEDGEMENTS}

The project was made possible with the financial support received from Qatar National Research Fund (a member of Qatar Foundation) under NPRP grant \# 7-1720-2-641. The statements made herein are solely the responsibility of the authors.

\section{REFERENCES}

ACI Committee 318, 2008. Building Code Requirements for Structural Concrete ( ACI 318M-08) and Commentary, Farmington Hills.

Al-Salloum, Y.A. et al., 2012. Experimental and Numerical Study for the Shear Strengthening of 
Reinforced Concrete Beams Using Textile-Reinforced Mortar. Journal of Composites ..., (February), pp.74-90. Available at: http://ascelibrary.org/doi/abs/10.1061/(ASCE)CC.1943-5614.0000239.

ASTM G1-03, 2011. Standard Practice for Preparing, Cleaning, and Evaluating Corrosion Test Specimens, West Conshohocken, PA. Available at: http://www.astm.org/Standards/G1.htm.

Babaeidarabad, S., Loreto, G. \& Nanni, A., 2014. Flexural Strengthening of RC Beams with an Externally Bonded Fabric-Reinforced Cementitious Matrix. Journal of Composites for Construction, 10.1061/(ASCE)CC.1943-5614.0000473., pp.1-12.

Baggio, D., Soudki, K. \& Noël, M., 2014. Strengthening of shear critical RC beams with various FRP systems. Construction and Building Materials, 66, pp.634-644. Available at: http://linkinghub.elsevier.com/retrieve/pii/S0950061814005996.

Brückner, a., Ortlepp, R. \& Curbach, M., 2006. Textile reinforced concrete for strengthening in bending and shear. Materials and Structures, 39(8), pp.741-748.

D’Ambrisi, A. \& Focacci, F., 2011. Flexural Strengthening of RC Beams with Cement-Based Composites. Journal of Composites for Construction, 15(5), pp.707-720.

Dong, J., Wang, Q. \& Guan, Z., 2013. Structural behaviour of RC beams with external flexural and flexural-shear strengthening by FRP sheets. Composites Part B: Engineering, 44(1), pp.604-612. Available at: http://linkinghub.elsevier.com/retrieve/pii/S1359836812001746.

Dong, J.F., Wang, Q.Y. \& Guan, Z.W., 2012. Structural behaviour of RC beams externally strengthened with FRP sheets under fatigue and monotonic loading. Engineering Structures, 41, pp.24-33. Available at: http://linkinghub.elsevier.com/retrieve/pii/S0141029612001423.

El-maaddawy, T. \& Refai, A. El, 2016. Innovative Repair of Severely Corroded T-Beams using FabricReinforced Cementitious Matrix Innovative Repair of Severely Corroded T-Beams Using FabricReinforced Cementitious Matrix. , (October 2015).

Hashemi, S. \& Al-Mahaidi, R., 2012a. Experimental and finite element analysis of flexural behavior of FRP-strengthened RC beams using cement-based adhesives. Construction and Building Materials, 26(1), pp.268-273.

Hashemi, S. \& Al-Mahaidi, R., 2012b. Flexural performance of CFRP textile-retrofitted RC beams using cement-based adhesives at high temperature. Construction and Building Materials, 28(1), pp.791-797. Available at: http://dx.doi.org/10.1016/j.conbuildmat.2011.09.015.

Loreto, G. et al., 2013. Performance of RC Slab-Type Elements Strengthened with Fabric-Reinforced Cementitious-Matrix Composites. American Society of Civil Engineers, pp.1-9.

Masoud, S. \& Soudki, K., 2006. Evaluation of corrosion activity in FRP repaired RC beams. Cement and Concrete Composites, 28(10), pp.969-977.

Pisani, M.A., 2007. Evaluation of Bending Strength of RC Beams Strengthened with FRP Sheets. , 10(4), pp.313-320.

Schladitz, F. et al., 2012. Bending load capacity of reinforced concrete slabs strengthened with textile reinforced concrete. , 40, pp.317-326. 